\title{
The Impact of Fiscal Policies on R\&D at the Firm Level
}

\author{
Yafeng $\mathrm{Hu}^{1}, \mathrm{Ke} \mathrm{Gao}^{2,3}$ \\ ${ }^{1}$ School of China Academy of Public Finance and Public Policy, Central University of Finance and Economics, Beijing, P. R. China \\ ${ }^{2}$ PBC School of Finance, Tsinghua University, Beijing, P. R. China \\ ${ }^{3}$ Development Research Center of Shandong Provincial People's Government, Jinan, P. R. China
}

Email address:

1023057500@qq.com (Yafeng Hu),gkfly@126.com (Ke Gao)

\section{To cite this article:}

Yafeng Hu, Ke Gao. The Impact of Fiscal Policies on R\&D at the Firm Level. Journal of Finance and Accounting.

Vol. 7, No. 1, 2019, pp. 17-21. doi: 10.11648/j.jfa.20190701.13

Received: December 20, 2018; Accepted: January 17, 2019; Published: February 1, 2019

\begin{abstract}
The existing researches about the effects of public policies on promoting enterprise innovation are mostly on large enterprises, but few on small and medium-sized enterprises. The literature on small and medium-sized enterprises in developing countries is even less. As an important part of the world economy and an important representative of developing countries, it is necessary to study the impact of China's public subsidies and tax incentives on the innovation and research and development of Chinese SMEs. Based on the relevant enterprise data, using the LSDV model, this paper empirically finds that the Chinese government's fiscal subsidy policies indeed promote enterprise innovation. After controlling for the year fixed effect and industry effect, government subsidies did stimulate enterprises' R\&D investment, but the stimulus effect was very weak. Considering the endogeneity of public subsidies, the author added the lag term of public subsidies into the model, and the promotion effect of the policy was significantly enhanced. With the expansion of enterprise scale and the passage of enterprise establishment years, enterprise innovation investment decreases. The conclusion of this paper provides a basis for the government to formulate relevant policies. Government subsidies should be increased for newly established companies and for small and micro businesses.
\end{abstract}

Keywords: Innovation, Financial Subsidies, Small and Medium-Sized Enterprises, Research and Development Expenditure

\section{Introduction}

On October 31, 2018, the political bureau of the CPC central committee held an economic meeting to evaluate and characterize the current economic situation in China. The meeting pointed out that in the first three quarters of this year, China's economic performance was on the whole stable with steady progress and maintained within an appropriate range. However, downward pressure on the economy is increasing, and some enterprises are facing more difficulties in their operations. The meeting proposed future work requirements from the six dimensions of "stabilizing employment, financing, foreign trade, foreign capital, investment and expectations". To stabilize foreign trade, some positive actions need to be taken to deal with the negative impact of a trade war between China and the United States. In order to enhance the competitiveness of enterprises, forming core technology is the key. The acquisition of technological advantages requires enterprises to invest research and development funds for technological innovation. Due to the spillover effect of technological innovation, relying only on enterprises' own investment will lead to insufficient supply of innovation. At present, China implements a positive fiscal policy, and large-scale tax and fee reduction measures are of great significance for releasing policy dividends to enterprises and enhancing the confidence of market and micro subjects. Enterprises should seize this opportunity, magnify the effect of policies, and effectively enhance their innovation capabilities according to their own actual conditions.

\section{Literature Review}

There is no unified conclusion about the effect of government public policy on enterprise innovation. Relevant researches can be divided into three categories. In the first category, some scholars believe that public policy promotes enterprise innovation. The second type of research, some 
scholars believe that public policy inhibits enterprise innovation. In the third category, other scholars believe that there is no significant or non-linear correlation between public policy and enterprise innovation.

In the first category, some scholars believed that public policy promoted enterprise innovation. Levy (1983) and Nadiri (1993) found that there was a positive correlation between government funding and enterprise R\&D [1-2]. Enterprise R\&D can be divided into basic research and applied research. Robson (1993) pointed out that there was a significant positive correlation between government funding and enterprise basic research, and there was a short-term positive correlation with enterprise applied research [3]. Falk (2007) used enterprise data for the first time to empirically test the effect of Australian federal R\&D support program on enterprise behavior, and the results showed that the federal R\&D support program enhanced the innovation ability of enterprises and enhanced their competitiveness [4]. Czarnitzki and Almus (2003) studied the average effect of total funding received by enterprises on enterprise innovation. The author believed that the number of staff and salary in the R\&D department of enterprises would cause selection bias on the selection of enterprises for subsidy. The endogeneity was controlled by the propensity matching score model. Empirical test showed that in east German enterprises, the R\&D investment of the funded enterprises increased by about $4 \%$ compared with that of the non-funded enterprises [5]. Cappelen (2012) used SkatteFUNN plan database to analyze the effect of the plan, and the results showed that the preferential tax policies of the plan stimulated the $R \& D$ process of new processes of enterprises, and to some extent stimulating the R\&D of new products of Norwegian enterprises [6]. Czarnitaki (2007), Busom (2004), Toole (2007), Tommy (2009) and Czarnitzki (2011) all found the same promotion effect of fiscal policies [7-11].

The second type of research, some scholars believed that public policy inhibited enterprise innovation. The1987 US government-funded semiconductor technology innovation program was designed to save the shrinking market share of 14 companies involved. Irwin (1996) evaluated the effect of the government-funded project on $R \& D$ expenditure, profitability and productivity of the funded enterprises. The results showed that the project reduced the total R\&D expenditure of the funded enterprises by 300 million dollars per year, and the negative correlation between the government-funded projects and the R\&D of enterprises [12]. Similarly, Wallsten (2000) took the research on the effect of SBIR program in the United States on enterprise $R \& D$ activities as an example to evaluate the impact of government industrial R\&D policies on private innovation. This paper also took into account endogenous problems caused by government policy selection bias and USES instrumental variables. By using the connected equation model, it could be found that enterprises with more employees and more R\&D experience were more likely to be funded. Government funding has completely squeezed out private investment in research and development [13]. Yao and Yu (2014) built an econometric model based on the production function, based on the questionnaire survey data of small and medium-sized enterprises in Guangdong province. They empirically tested the influence of different levels of subsidies on intellectual property rights of small and medium-sized enterprises in science and technology from the perspective of central government financial subsidies and local government financial subsidies. The results showed that the central financial subsidy had no significant influence on the formation of intellectual property assets of small and medium-sized enterprises. Local financial subsidies had a significant positive correlation with the formation of intellectual property assets of small and medium-sized enterprises. Fiscal subsidies had a significant substitution effect on innovation and R\&D investment of small and medium-sized enterprises [14]. Mamuneas and Nadiri (1996), Gorg and Strobl (2006) and Guellec and Pottelsberghe (2003) also found similar conclusions [15-17].

In the third category, other scholars believed that there was no significant or non-linear correlation between public policy and enterprise innovation. Zhou and wu (2017) studied the innovation effect of government subsidies on small and medium-sized enterprises, and added the enterprise characteristic of enterprise risk level. Based on the SME board data of Shenzhen stock exchange, the empirical test showed that the government subsidy intensity did not have a simple linear impact on the technological innovation of enterprises, but a u-shaped relationship [18]. Gonzalez (2008) divided the total growth effect of enterprise $R \& D$ into two parts: enterprises' spontaneous innovation activities to maintain their market dominance; Enterprises' passive participation in R\&D activities caused by public support policies. Considering the continuous variable of support policy included in the propensity matching model, the bias-corrected matching estimator was used to find matching companies. Based on the data of Spanish manufacturing enterprises, empirical results showed that there was no substitution effect between public $R \& D$ expenditure and private enterprise expenditure [19]. Li (2017) pointed out that when analyzing the incentive effect of fiscal subsidy policies on R\&D investment of enterprises, existing studies did not remove the "noise" of subsidies that were not related to innovation of enterprises, such as export earnings discount, social security subsidy and fiscal discount, which would affect the reference significance of conclusions. After removing these "noise" subsidies, the author found that financial innovation subsidies did not play a role in encouraging enterprises to invest in innovation [20].

In short, the academic community has not reached an agreement on the effect of government fiscal and tax policies on enterprise innovation. Most literature focuses on large enterprises and lacks in-depth research on samples of small and medium-sized enterprises. This paper takes the "small and medium-sized board" and "growth enterprise market" listed companies of Shenzhen stock exchange of China as the research object. The author attempts to analyze the impact of government subsidies on the R\&D innovation of small and 
medium-sized enterprises.

\section{Model Design and Empirical Test}

Firstly, Correlation variables and sample descriptions. Sample description: the enterprise characteristic data selected in this paper is from the data of "small and medium-sized board" and "growth enterprise market" of Shenzhen stock exchange in China from 2012 to 2016 and the Wind database. There are 1361 observations in total. The patent data of enterprises is obtained from the patent statistical annual report on the website of the state intellectual property office of China. And the public subsidy data of enterprises is obtained from the annual financial statements of enterprises.
There are five periods of data, which are short panel data.

The explained variable is the intensity rdi of the enterprise's annual R\&D expenditure. The main explanatory variable is govsi (financial subsidy amount accepted by enterprises divided by income from main business of enterprises). Referring to Deng and Yang (2011), Li (2017), and Qin (2012), setting control variables for enterprise age, the company net profit neti, technical staff accounted for tecpeo (the ratio of number of technical staff employees and staff), enterprise scale lnta (the natural logarithm of total assets ta) and netir (the ratio of enterprise net profit and revenue) [20-22]. The main conditions of each indicator are shown in table 1.

Table 1. Description of variables and indicators.

\begin{tabular}{|c|c|c|c|c|c|}
\hline Variable & Obs & Mean & Std. Dev. & Min & $\operatorname{Max}$ \\
\hline$r d i$ & 1,361 & 5.191562 & 6.583179 & 0 & 72.75 \\
\hline age & 1,361 & 15.47979 & 4.587683 & 4 & 37 \\
\hline govsi & 1,361 & 188.6434 & 368.4302 & 0 & 6948.699 \\
\hline $\ln t a$ & 1,361 & 11.64496 & 0.619348 & 9.313615 & 14.43658 \\
\hline netir & 1,361 & 0.090333 & 0.464756 & -14.3602 & 0.908108 \\
\hline
\end{tabular}

Secondly, The empirical research. According to the existing research, this paper sets the model as follows:

$$
\mathrm{Y}_{\mathrm{it}}=\alpha g o v s \mathrm{i}_{\mathrm{it}}+\beta \mathrm{Xit}+\text { yearfe }+\mathrm{in} \_ \text {confe }+\varepsilon_{\mathrm{it}}
$$

Among them, the main explanatory variable is govsi (the government public subsidy intensity), and $\mathrm{X}$ is the control variable. The sample data type is non-equilibrium panel data, and the yearfe and in_confe industry variables are added to the model to control the fixed effect. The main regression results are shown in table 2:

Table 2. The test of the impact of the government subsidies on enterprise $R \& D$ innovation.

\begin{tabular}{|c|c|c|c|c|c|}
\hline & (1) & (2) & (3) & (4) & (5) \\
\hline VARIABLES & rdi & rdi & rdi & rdi & rdi \\
\hline \multicolumn{6}{|l|}{ rdi } \\
\hline \multirow[t]{2}{*}{ age } & -0.00244 & $-0.110 * * *$ & $-0.161 * * *$ & $-0.149 * * *$ & $-0.149 * * *$ \\
\hline & $(-0.0693)$ & $(-3.326)$ & $(-3.625)$ & $(-3.355)$ & $(-3.887)$ \\
\hline \multirow[t]{2}{*}{ govsi } & $0.00490 * *$ & $0.00872 * * *$ & $0.0134 * * *$ & & \\
\hline & $(2.381)$ & $(4.426)$ & $(4.881)$ & & \\
\hline \multirow[t]{2}{*}{ tecpeo } & $18.59 * * *$ & $18.03 * * *$ & $23.23 * * *$ & $22.86 * * *$ & $22.86^{* * *}$ \\
\hline & (18.33) & $(18.75)$ & $(18.32)$ & $(17.87)$ & $(8.951)$ \\
\hline \multirow[t]{2}{*}{ lnta } & 0.00420 & -0.312 & $-0.909 * * *$ & $-0.812 * *$ & $-0.812 * * *$ \\
\hline & $(0.0157)$ & $(-1.250)$ & $(-2.758)$ & $(-2.446)$ & $(-2.932)$ \\
\hline \multirow[t]{2}{*}{ netir } & -0.293 & -0.0562 & & & \\
\hline & $(-0.851)$ & $(-0.178)$ & & & \\
\hline \multirow[t]{2}{*}{ 2013. year } & & $6.131 * * *$ & & & \\
\hline & & $(11.68)$ & & & \\
\hline \multirow[t]{2}{*}{ 2014. year } & & $5.821 * * *$ & 0.0344 & -0.0292 & -0.0292 \\
\hline & & (11.31) & $(0.0587)$ & $(-0.0499)$ & $(-0.0495)$ \\
\hline \multirow[t]{2}{*}{ 2015. year } & & $6.894 * * *$ & $1.442 * *$ & $1.390 * *$ & $1.390 * *$ \\
\hline & & (13.97) & (2.494) & $(2.408)$ & $(2.289)$ \\
\hline \multirow[t]{2}{*}{ 2016. year } & & $7.032 * * *$ & $1.608 * * *$ & $1.021 *$ & $1.021 * *$ \\
\hline & & (14.28) & (2.797) & (1.828) & $(2.002)$ \\
\hline \multirow[t]{2}{*}{ 2.ind_con } & & 3.870 & $5.978 * *$ & $6.122 * *$ & $6.122 * * *$ \\
\hline & & (1.606) & (2.017) & $(2.065)$ & $(9.585)$ \\
\hline \multirow[t]{2}{*}{ 3.ind_con } & & -0.0882 & 1.615 & 2.251 & 2.251 \\
\hline & & $(-0.0299)$ & $(0.358)$ & $(0.498)$ & (1.621) \\
\hline \multirow[t]{2}{*}{ 4.ind_con } & & -1.799 & 6.162 & 6.172 & $6.172 * * *$ \\
\hline & & $(-0.459)$ & $(0.931)$ & $(0.933)$ & $(6.677)$ \\
\hline \multirow[t]{2}{*}{ 6.ind_con } & & 1.586 & 3.250 & 3.474 & $3.474 * * *$ \\
\hline & & $(0.547)$ & $(0.898)$ & $(0.960)$ & $(4.273)$ \\
\hline \multirow[t]{2}{*}{ L.netir } & & & $0.902 * *$ & $0.704^{*}$ & $0.704 * *$ \\
\hline & & & $(2.473)$ & (1.926) & $(2.284)$ \\
\hline
\end{tabular}




\begin{tabular}{|c|c|c|c|c|c|}
\hline & (1) & (2) & (3) & (4) & $(5)$ \\
\hline VARIABLES & rdi & rdi & rdi & rdi & rdi \\
\hline \multicolumn{6}{|l|}{ rdi } \\
\hline L.govsi & & & & $\begin{array}{l}0.0123^{* * * *} \\
(4.999)\end{array}$ & $\begin{array}{l}0.0123 * * * \\
(3.394)\end{array}$ \\
\hline Constant & $\begin{array}{l}0.583 \\
(0.186)\end{array}$ & $\begin{array}{l}-3.431 \\
(-0.893)\end{array}$ & $\begin{array}{l}6.592 \\
(1.324)\end{array}$ & $\begin{array}{l}5.288 \\
(1.053)\end{array}$ & $\begin{array}{l}5.288 \\
(1.482)\end{array}$ \\
\hline Observations & 1,346 & 1,346 & 943 & 943 & 943 \\
\hline $\mathrm{R}$-squared & 0.212 & 0.351 & 0.342 & 0.343 & 0.343 \\
\hline
\end{tabular}

t-statistics in parentheses

$* * * \mathrm{p}<0.01, * * \mathrm{p}<0.05, * \mathrm{p}<0.1$

Where column (1) in the table is listed as ordinary OLS regression, it is found that the govsi coefficient, the main explanatory variable, is positive and significant, indicating that the government's public subsidy promotes the R\&D investment of enterprises to some extent. However, because the sample is panel data, ordinary OLS regression results are only for reference. In column (2) regression, the LSDV method is used to control industry variables and year variables. The results show that the coefficient of govsi, is almost twice that of OLS regression coefficient and becomes more significant. The possible reason is that after controlling the industry variables, the interference effect of the differences between industries on the estimation results is weakened. In addition, considering the lag effect of enterprise net profit on enterprise $R \& D$ investment, in column (3) and (4) regression, The 1. neti (a lag variable of the first phase of enterprise net profit related indicators) is added. The results showed that the lag variable of net profit significantly promotes the R\&D input of the enterprise, which may be explained as that the current net profit of the enterprise is distributed to the R\&D department of the year, and the effect could not be shown until the next year, which is in line with the general objective law. Similarly, the first-stage lag variable of government subsidies is also taken into account. In column (4), the lag item of government subsidies significantly promotes the R\&D investment of enterprises. The government subsidy lagging terms are also be taken into account the endogeneity of government subsidy policies. The coefficient of lagging terms is larger than OLS regression coefficient, and the significance is also be improved. The column (5) adopts the robust standard error on the basis of column (4). The coefficient of government financial subsidy does not change, and still significant, indicating the robustness of the measurement results in this paper. Owing to the limited space, and some industry variables are not shown in table 2 .

In this paper, the natural logarithm of the total assets of the enterprise is used to represent the scale of the enterprise, and the establishment time of the enterprise represents the age of the enterprise. The empirical results show that with the increase of enterprise scale, the innovation investment of enterprises is decreasing. With the establishment of the enterprise time, the innovation investment of the enterprise also decreases. The possible reasons are as follows. Large enterprises may face little competitive pressure in their own fields, and occupy a relatively large market share. They can obtain more market profits through their own advantages, and do not need to invest too much research and development funds for technological innovation. Enterprises with a long history of establishment may have formed technical advantages over other enterprises due to their experience and technology accumulation in this field. This type of enterprise attaches more importance to the maintenance of existing market and technological advantages, and is not willing to innovate. Another possible reason is that older companies have reached the decline stage of their own development and have no remaining resources to invest in research and development.

\section{Conclusion}

From the above analysis, the conclusion is that China's public financial subsidy policy does promote enterprises' $R \& D$ investment. Moreover, it is found that with the growth of enterprise scale and establishment years, the innovation investment of enterprises decreases accordingly. Therefore, in the future policy making process, the government should tilt the financial subsidy funds to small enterprises and enterprises with shorter establishment years. At the same time, the government should strengthen the performance evaluation on the use of fiscal subsidy funds and improve the efficiency of the fiscal subsidy funds. In addition, the government should increase investment, and encourage the cooperation of industry-university-research in order to enhance the innovation willingness and efficiency of the whole society.

\section{References}

[1] David M. Levy, Nestor E. Terleckyj. Effects of Government R\&D on Private R\&D Investment and Productivity: A Macroeconomic Analysis. The Bell Journal of Economics, Vol. 14, No. 2 (Autumn, 1983), pp. 551-561.

[2] Nadiri, M. Ishaq. "Innovations and Technological Spillovers." National Bureau of Economic Research Working Paper Series No. 4423 (1993).

[3] Robson, Martin T. "Federal Funding and the Level of Private Expenditure on Basic Research." Southern Economic Journal 60, no. 1 (1993): 63-71. doi:10.2307/1059931.

[4] Falk, Rahel. "Measuring the Effects of Public Support Schemes on Firms' Innovation Activities: Survey Evidence from Austria." Research Policy 36, no. 5 (2007/06/01/ 2007): 665-79. 
[5] Almus, M. and D. Czarnitzki (2003). "The Effects of Public R\&D Subsidies on Firms' Innovation Activities." Journal of Business \& Economic Statistics 21 (2): 226-236.

[6] Cappelen, Å., A. Raknerud, et al. (2012). "The effects of R\&D tax credits on patenting and innovations." Research Policy 41 (2): $334-345$.

[7] Czarnitzki, Dirk, Bernd Ebersberger, and Andreas Fier. "The Relationship between R\&D Collaboration, Subsidies and R\&D Performance: Empirical Evidence from Finland and Germany." Journal of Applied Econometrics 22, no. 7 (2007/12/01 2007): 1347-66.

[8] Blanes, J. V. and I. Busom (2004). "Who participates in R\&D subsidy programs? The case of Spanish manufacturing firms." Research Policy 33 (10): 1459-1476.

[9] Andrew A. Toole (2007). "Does Public Scientific Research Complement Private Investment in Research and Development in the Pharmaceutical Industry?" The Journal of Law and Economics 50 (1): 81-104.

[10] Clausen, T. H. (2009). "Do subsidies have positive impacts on R\&D and innovation activities at the firm level?" Structural Change and Economic Dynamics 20 (4): 239-253.

[11] Czarnitzki, D., P. Hanel, et al. (2011). "Evaluating the impact of R\&D tax credits on innovation: A micro econometric study on Canadian firms." Research Policy 40 (2): 217-229.

[12] Douglas A. Irwin, Peter J. Klenow. (1996). High-tech R\&D subsidies Estimating the effects of Sematech, Journal of International Economics, Volume 40, Issues 3-4, 323-344.

[13] Wallsten, S. J. (2000). "The Effects of Government-Industry R\&D Programs on Private R\&D: The Case of the Small Business Innovation Research Program." The RAND Journal of Economics 31 (1): 82-100.
[14] Yu ke, Yao Fengmin (2014). The Impact of Financial Subsidies on the Formation of Intellectual Property Rights of SMEs. Public Finance Research (09):61-64.

[15] Theofanis P. Mamuneas, M. IshaqNadiri. (1996). Public R\&D policies and cost behavior of the US manufacturing industries, Journal of Public Economics, Volume 63, Issue 1, Pages 57-81.

[16] Holger Görg, Eric Strobl, Do Government Subsidies Stimulate Training Expenditure? Micro econometric Evidence from Plant-Level Data. Southern Economic Journal Vol. 72, No. 4 (Apr., 2006), pp. 860-876.

[17] Guellec, D. and B. Van Pottelsberghe De La Potterie (2003). "The impact of public R\&D expenditure on business R\&D." Economics of Innovation and New Technology 12 (3): 225-243.

[18] Zhou Ming, Wu Cuiqing (2017). The influence of government subsidies on small and medium-sized enterprise technology innovation. Science Research Management 38 (S1):574-580.

[19] González, X. and C. Pazó (2008). "Do public subsidies stimulate private R\&D spending?" Research Policy 37 (3): 371-389.

[20] LI Wangfu, DU jing, et al (2017). Do R\&D Subsidies Really Stimulate Firms'R\&DSelf -financing Investment: New Evidence from China's Listed Firms. Journal of Financial Research (10):130-145.

[21] DENG Ziji, YANG Zhihong (2011). Theoretic and Empirical Analysis of Fiscal and Tax Policies Inducing Enterprises' Technological Innovation. Finance \& Trade Economics (05):5-10+136.

[22] Qin jun. (2011). The financial support system for high-tech SMEs' innovation. Science Research Management 32 (01):79-88. 